\title{
INFRARED ABSORPTION SPECTRA OF SOME PLANT PIGMENTS
}

\author{
By R. Stair and W. W. Coblentz
}

ABSTRACT

An important study of the properties of matter is the effect of chemical constitution upon the spectral absorption of a substance.

The present contribution to this subject pertains to the infrared spectrum, extending to about $15 \mu$.

A description is given of the absorption spectra, to about $15 \mu$ in the infrared, of the following plant pigments and derivatives: chlorophyll, carotin, xanthophyll, ethyl chlorophyllide, phytol, pheophytin, and copper pheophytin.

The data were obtained by means of a mirror spectrometer, vacuum thermopile and iron-clad Thomson galvanometer described in previous publications.

Changes in the absorption spectrum of carotin, accompanying oxidation, are described.

In general, the results are similar to those observed on the highly colored aniline dyes, in which there is an intense, wide absorption band in the short wave lengths, and the infrared absorption spectrum is composed of numerous small absorption bands, in contrast with substances having a simpler chemical structure, in which the absorption bands are less numerous, more intense, and more sharply defined.

Page

I. Introduction

II. Instruments and methods

III. Spectral transmission data. 704

1. Chlorophyll

2. Carotin

3. Xanthophyll

4. Ethyl chlorophyllide... 707

5. Phytol_..... 708

6. Pheophytin 708

7. Copper pheophytin

IV. Discussion of the data

V. Bibliography

\section{INTRODUCTION}

An important study of the properties of matter is the effect of chemical constitution upon the spectral absorption of a substance. The present contribution to this subject pertains to the deep infrared spectrum, extending to about $15 \mu$.

Through the generosity of Dr. F. M. Schertz of the Bureau of Chemistry and Soils, who presented us with samples of materials which he had prepared, we have been able to study the infrared absorption spectra of plant pigments (carotin, chlorophyll, and xanthophyll) and derivatives of these materials (1). ${ }^{1}$

1 Figures in parentheses here and throughout the text indicate references given in the bibliography at the end of this paper. 
Prior to this investigation but little had been done $(2,4)$ on the infrared absorption spectra of plant pigments, in which it is now found, as previously observed in some of the aniline dyes (5), that the absorption spectrum is composed of numerous small bands, in contrast with substances having a simpler chemical structure, in which the absorption bands are less numerous, more intense, and more sharply defined.

Data on the visible and ultraviolet absorption spectra of carotin and xanthophyll and the changes accompanying oxidation are given in a recent paper by McNicholas (11).

\section{INSTRUMENTS AND METHODS}

For a more detailed discussion of the experimental procedure, reference is made to previous publications $(6,7,8,9)$. The spectroradiometer consisted of a mirror spectrometer, with mirrors $50 \mathrm{~cm}$ in focal length. A fluorite prism was used in exploring the spectral region of $1 \mu$ to $8 \mu$ and a rock salt prism for the region to $15 \mu$. For the fluorite prism the slit width decreased from $0.17 \mu$ at $2 \mu$ to $0.05 \mu$ at $6 \mu$. For rock salt, the slit width decreased from $0.2 \mu$ at $6 \mu$ to $0.085 \mu$ at $14 \mu$ (see fig. 1).

The spectral radiation was measured with a vacuum thermopile and an iron-clad Thomson galvanometer. The source of radiation was a Nernst glower focused upon the entrance slit by means of a concave mirror.

The containers for the liquids were made of cleavage plates of rock salt, or polished plates of fluorite, placed at the entrance slit. The solid films were deposited by evaporation of liquid solutions or by melting some of the material on similar plates of rock salt, or fluorite. Variations from the standard procedure are noted in the text.

\section{SPECTRAL TRANSMISSION DATA}

Under this caption a brief description is given of the material examined, and the general properties of the absorption spectrum as compared with chemically related substances.

\section{CHLOROPHYLL}

The samples examined consisted of the two chlorophylls $a, \mathrm{C}_{55} \mathrm{H}_{72}$ $\mathrm{O}_{5} \mathrm{~N}_{4} \mathrm{Mg}$ and $b, \mathrm{C}_{55} \mathrm{H}_{70} \mathrm{O}_{6} \mathrm{~N}_{4} \mathrm{Mg}$ unseparated as obtained (1) from wood nettles, in the ratio of about two parts of $a$ to one of $b$.

The transmission curves (fig. 1) were obtained upon samples prepared by evaporation of an alcoholic solution of the pigment on cleavage plates of rock salt, leaving an almost (visually) opaque film, uniformly covering the plate. The curve for the shorter wave lengths was observed by using a fluorite prism. A rock salt prism was employed for the curve, extending from $5.88 \mu$ to $14 \mu$.

According to Van Gulik (3) whose transmission measurements, using a quartz prism, extend to $3.6 \mu$ in the infrared, the $a$-component of chlorophyll has its maximum absorption at $0.65 \mu$, with a weak absorption band at $0.8 \mu(4)$. The $b$-component has its maximum absorption at $0.63 \mu$. According to his measurements, the strong absorption band at $3.43 \mu$ (fig. 1) is a complex of two bands at $3.4 \mu$ and $3.5 \mu$. Using a rock salt prism, the writers have observed a similar 
complexity, which is probably owing to errors resulting from the smaller dispersion of this kind of prism.

A conspicuous feature of the absorption spectrum of chlorophyll is its great opacity in the short wave lengths and its relatively high

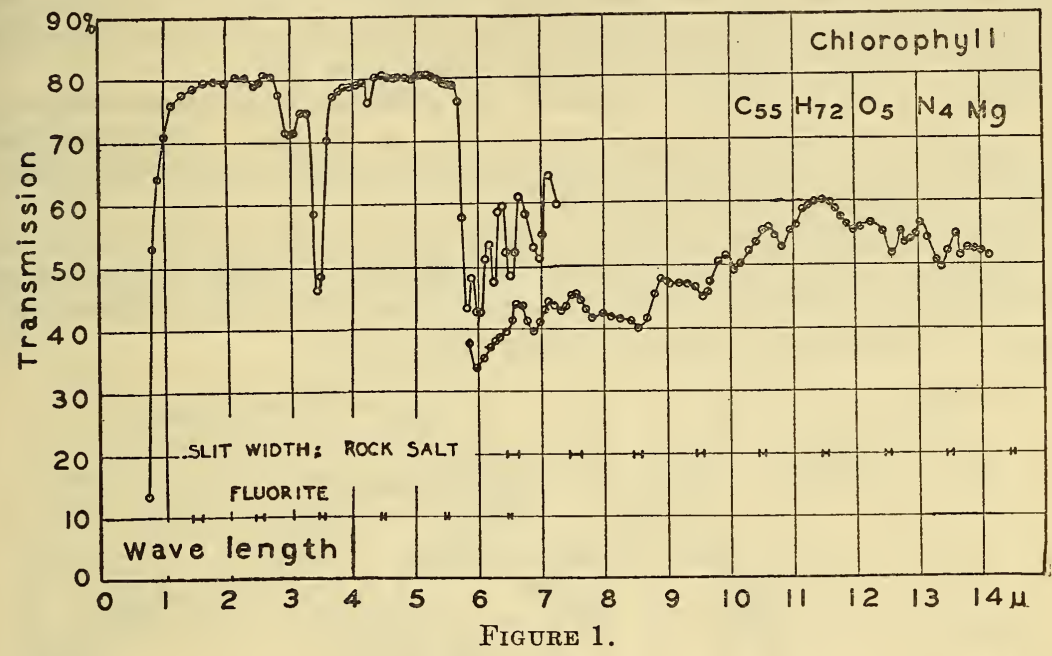

transparency in the infrared, as previously observed in some of the aniline dyes (5).

\section{CAROTIN}

A film of carotin $\left(\mathrm{C}_{40} \mathrm{H}_{56}\right)$ was prepared by gently heating the fine crystals on a cleavage plate of rock salt.

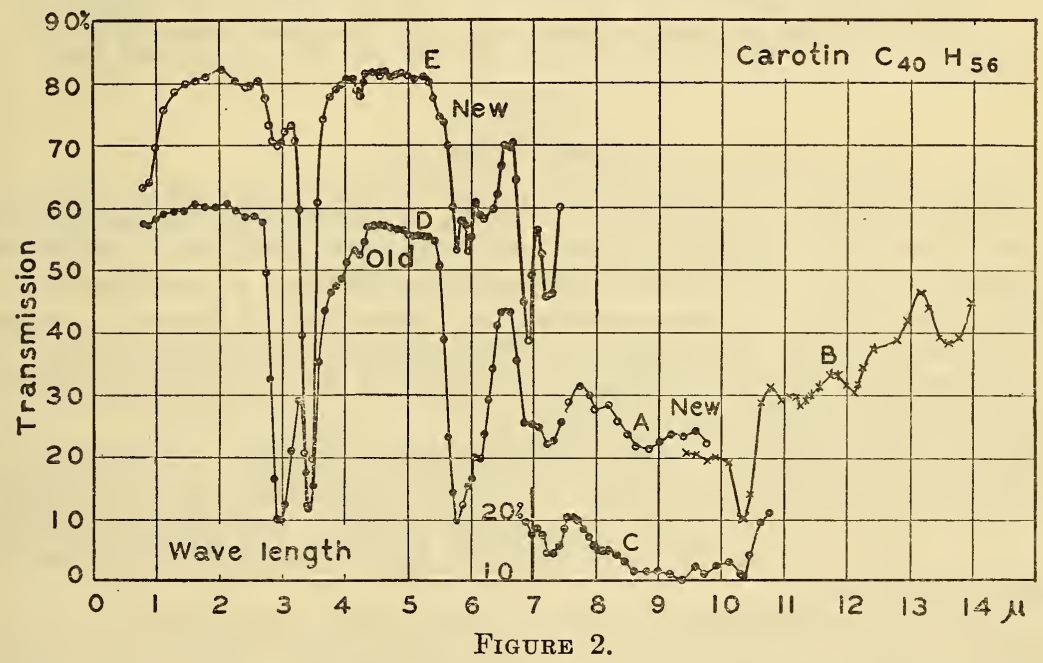

In figure 2, curve $A$ illustrates the spectral transmission of a freshly prepared film of carotin; curve $B$ was obtained the next day, and curve $C$ was obtained on the same sample 12 days later.

After the lapse of about two and one half years this sample was reexamined in the shorter wave lengths, using a fluorite prism, with 
the result shown in curve $D$ (marked "old"). A new sample, freshly prepared in the same manner as was the older one, gave the result shown in curve $E$ (marked "new").

Chemically, this pigment is a strongly unsaturated auto-oxidizable hydrocarbon, having the structural formula $\left(\mathrm{C}_{5} \mathrm{H}_{7}\right)_{\mathrm{x}}$. Thin laminae (crystals) appear red or yellowish-red in transmitted light; bleaching to yellow or fairly colorless films on standing in air.

There is no similarity between the infrared absorption spectrum of carotin and that of cymene, $\mathrm{C}_{10} \mathrm{H}_{14}$ or $\left(\mathrm{C}_{5} \mathrm{H}_{7}\right)_{2}$, (1), previously examined (10). Evidently the structural bonding of the atoms within the molecule is entirely different.

The question arises as to the origin of the strong absorption band in carotin and in xanthophyll in the region of $2.98 \mu$, characteristic of substances having $\mathrm{N}-\mathrm{H}$ bonds, as in pyrrol (10), and in chlorophyll; also in substances (alcohols) having OH groups.

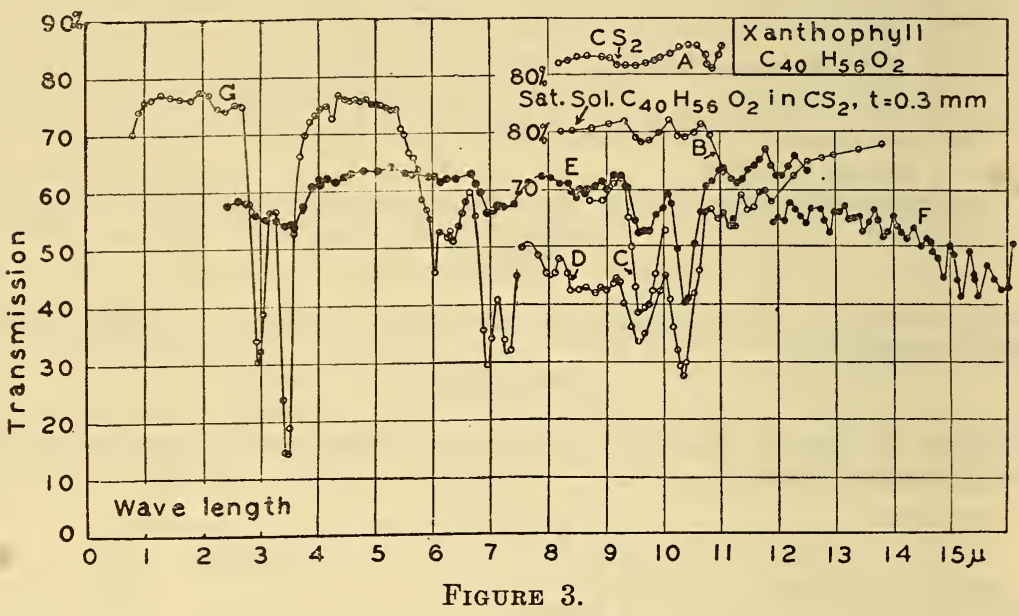

\section{XANTHOPHYLL}

Various means of applying a film of xanthophyll $\left(\mathrm{C}_{40} \mathrm{H}_{56} \mathrm{O}_{2}\right)$ on a plate of rock salt were employed before suitable films were produced. In addition to the solid films, a saturated solution of xanthophyll in $\mathrm{CS}_{2}$ (curve $B$, fig. 3) was examined in the region of $8 \mu$ to $11 \mu$ where the solvent (curve $A$ ) shows but little selective absorption (10). It is evident that the strong bands at $9.6 \mu$ and $10.4 \mu$ belong to xanthophyll and not to the solvent, $\mathrm{CS}_{2}$.

Some of the better curves obtained from solid films of xanthophyll are also reproduced in figure 3 . Curve $C$ shows the selective absorption in the region of $9 \mu$ to $10 \mu$ using a freshly prepared film melted on rock salt. Curve $D$ was obtained from the same film two to three days later.

A new film evaporated from alcohol between two plates of rock salt, then melted, gave curve $E(2.3 \mu$ to $12.5 \mu)$. The observations $11.9 \mu$ to $16.1 \mu$ (curve $F$ ) were made on the same sample 12 days later. 
A new sample melted on rock salt (curve $G$ ) gave some interesting absorption bands in the shorter wave lengths as observed with a fluorite prism.

A conspicuous feature of the infrared spectrum of xanthophyll is the sharply defined absorption bands at $3.43 \mu, 6.86 \mu$, and $7.3 \mu$, found in compounds containing $\mathrm{CH}_{2}$ and $\mathrm{CH}_{3}$ groups of atoms (10); also at $2.95 \mu$ as found in compounds having OH-groups. The absorption bands at $9.6 \mu$ and $10.3 \mu$ are strong, the latter being in common also in carotin.

Xanthophyll, $\mathrm{C}_{40} \mathrm{H}_{56} \mathrm{O}_{2}$, differs from carotin, $\mathrm{C}_{40} \mathrm{H}_{56}$, by the presence of oxygen. In the short wave length region of the infrared, there is but little difference in the absorption spectra of these two compounds. On the other hand, in the long wave lengths, (the pure rotational effect of the molecule) at $8 \mu$ to $10 \mu$, where carotin shows a wide region

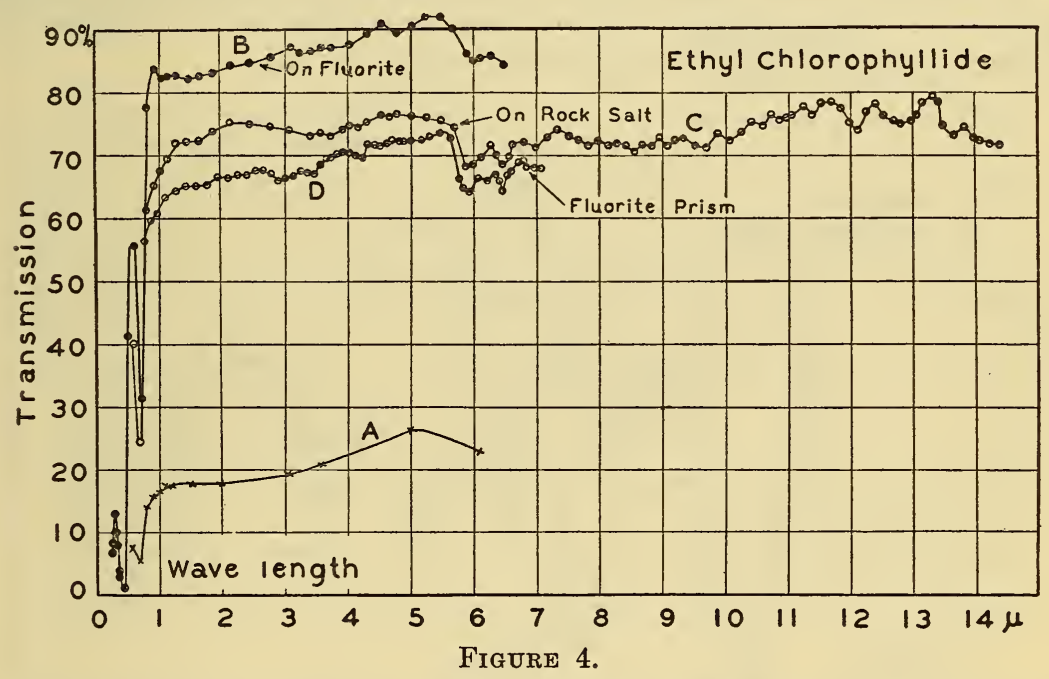

of absorption, xanthophyll has a distinct absorption band with a maximum at $9.6 \mu$.

\section{ETHYL CHLOROPHYLLIDE}

By the action of an enzyme, chlorophyllase, upon an alcoholic solution of chlorophyll, ethyl chlorophyllide is obtained (1).

The best samples of ethyl chlorophyllide were prepared by placing the crystalline material upon plates of rock salt (previously heated to remove the moisture) or fluorite, and dissolving it with alcohol. After evaporation, the pigment remained in a smooth, homogenous film that appeared green by transmitted light.

In figure 4 , curve $A$ was obtained by using a thin film on fluorite. Although the film appeared very homogenous, so that distant objects could be seen distinctly through it, the transmission is low in contrast with curve $B$ which was obtained from a similarly prepared film. In addition to the infrared, the transmission bands in the green and in the ultraviolet spectrum (absorption maxima at $0.4 \mu$ and $0.7 \mu$ are shown for this sample (dots ...). 
Another film (curve $C$ ) was examined from $0.70 \mu$ to $14.36 \mu$. About two and one half years later, this film was reexamined in the shorter wave lengths (curve $D$ ), using a fluorite prism) showing but little change in transmission.

A characteristic feature of the infrared absorption spectrum of ethyl chlorophyllide is the almost entire absence of strong bands of selective absorption, such as appear in the shorter wave lengths.

\section{PHYTOL}

Phytol $\left(\mathrm{C}_{20} \mathrm{H}_{39} \mathrm{OH}\right)$ is an unsaturated primary alcohol, with an open chain of carbon atoms (1). The sample examined was a transparent light yellow liquid obtained from crude chlorophyll. It is obtainable also in the preparation of ethyl chlorophyllide (1).

The samples were examined in a cell $0.3 \mathrm{~mm}$ in thickness, having windows of thin cleavage pieces of rock salt; also as a capillary film between two matched cleavage sections of rock salt.

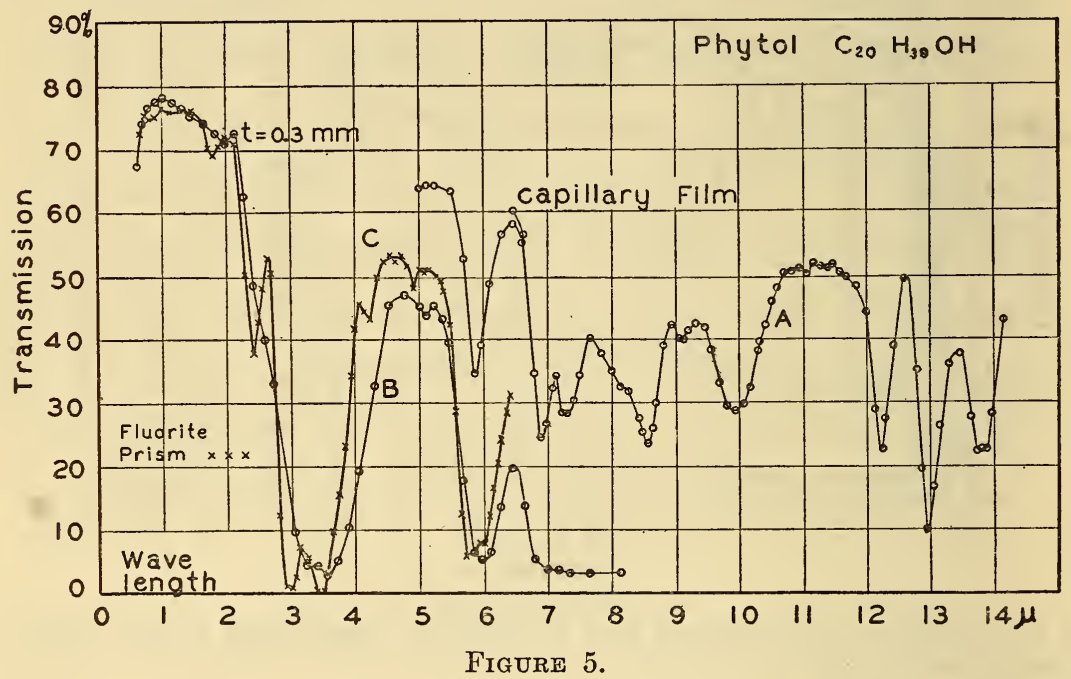

The capillary film of liquid was obtained by splitting a crystal of rock salt (size 5 by 3 by $1 \mathrm{~cm}$ ) into two parts, each about $5 \mathrm{~mm}$ in thickness, reassembling it accurately and placing a drop of the liquid in a conical or V-shaped depression, cut into one side, along the line of cleavage of the crystal. By capillary action, the film of liquid spreads uniformly, without interruptions by air bubbles, between the two plates.

A conspicuous feature of the infrared absorption spectrum is the intense absorption bands, particularly the approximately harmonic bands (10) at $3.43 \mu, 6.86 \mu$, and $13.8 \mu$; also the bands at $2.95 \mu$ and $5.9 \mu$ characteristic of (alcohols) substances containing $\mathrm{OH}-$ and NH-bonding.

\section{PHEOPHYTIN}

The compound, pheophytin (chemical formula not given) is a dark-colored, waxy substance formed by the action of oxalic acid upon chlorophyll (1). The transmission spectrum is shown by the 
circles (o o o) in figure 6. For the region $6.6 \mu$ to $14 \mu$ a film of the wax was melted on a plate of rock salt. From $0.8 \mu$ to $7 \mu$, where the fluorite prism was used, the film was prepared by dissolving the pheophytin in xylol, which was allowed to evaporate.

\section{COPPER PHEOPHYTIN}

Copper pheophytin (14.97 percent copper) is a dark substance having a greenish yellow color by transmitted light and a faint purplish color by reflected light.

The transmission curve is shown (dots ...) in figure 6. The film examined in the spectral region from $7 \mu$ to $14 \mu$ was obtained by evaporation of a benzol solution of the material on rock salt. For the region of $0.8 \mu$ to $7 \mu$ the film was prepared by evaporation of a solution of copper pheophytin dissolved in xylol.

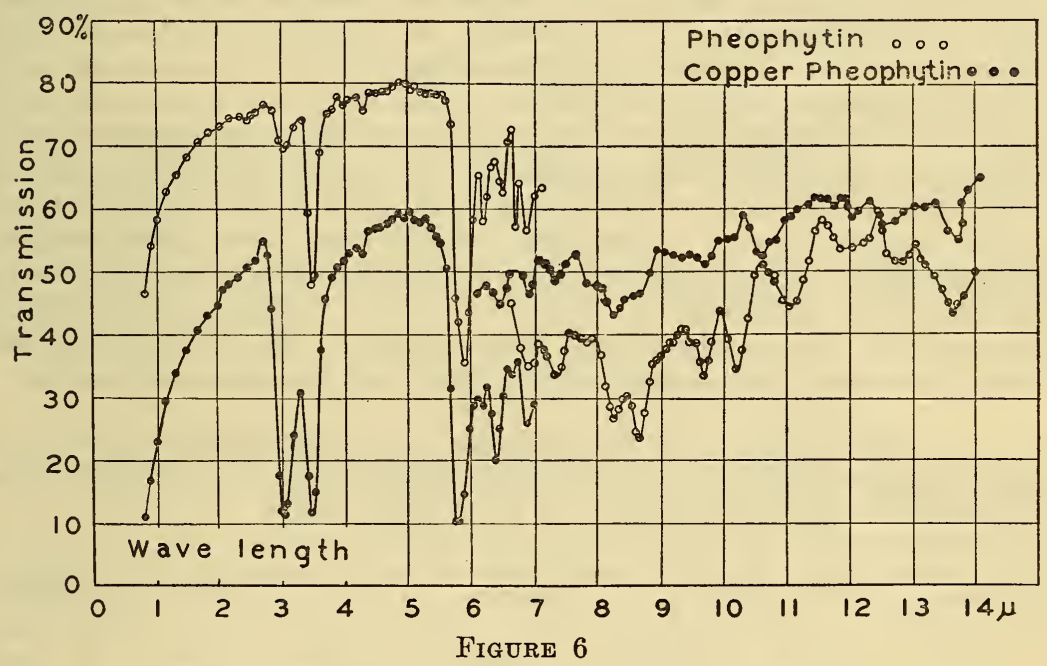

A conspicuous feature of the absorption spectra of pheophytin and copper pheophytin is the numerous absorption bands, some of which are in close coincidence with those of other chlorophyll derivatives described in this paper.

\section{DISCUSSION OF THE DATA}

Present conceptions of the mechanism of absorption (some of which are now accepted as axiomatic) are built upon evidence, gathered slowly and laboriously, step by step, during the past 3 to 4 decades, showing: (a) that the absorption is intra-molecular; (b) that the absorption spectrum of a compound is not the composite of the absorption bands of the constituent elements; $(c)$ that the grouping or bonding of the atoms determines the character of the absorption spectrum; and $(d)$ that the arrangement of the groups within the molecule (e.g., the $\mathrm{CH}_{3}$ group in the ortho-, meta-, and para-position in the benzene ring), as well as the atomic weight of the basic element (e.g., $\mathrm{Mg}, \mathrm{Pb}$, in the carbonates, sulphates, and nitrates) affect the position of the maximum absorption (10), (14). 
The first observations (10) of closely harmonic absorption bands (e.g., the hydrocarbon absorption bands at $0.86 \mu, 1.71 \mu, 3.43 \mu, 6.86 \mu$, and $13.8 \mu$ to $14 \mu$; and the $\mathrm{OH}$ - or NH-bonding with maximum at $2.95 \mu, 5.9 \mu$, and $11.8 \mu$ to $12 \mu$, which in those days were considered as erroneous or accidental) have found a place in present-day speculations of the mechanism of absorption which now assumes each absorption band to be a fundamental, a harmonic, or a combination, involving vibrational and rotational states of the molecule.

In fact, the correlation of theory with experimental data has progressed to such a stage that, in a recent contribution on this subject, Cross and Daniels (12) have reconstructed the whole observed infrared absorption spectrum of certain ethyl halides by a judicious selection of fundamentals with their first harmonics, and combinations of these absorption bands.

Following this procedure, by selecting certain large absorption bands as fundamentals, it is possible to calculate harmonics and combinations that appear to coincide closely with our experimentally observed maxima, within the limits of the accuracy attainable with the narrow dispersion that can be used in making such measurements.

However, in view of the complexity of the chemical structure of the compounds studied, and the large number of ill-defined absorption maxima recorded (some unresolved), the writers do not feel justified in attempting to classify the maxima of the bands of selective absorption which are recorded in table 1 . By a judicious selection of fundamentals and combinations there would be no difficulty in calculating maxima that coincide with many of the observed bands.

TABLE 1.-Observed wave length $(\lambda)$ in microns $(\mu)$ and wave number $\left(\mathrm{cm}^{-1}\right)$ of the more important absorption maxima of chlorophyll, carotin, xanthophyll, ethyl chlorophyllide, phytol, pheophytin, and copper pheophytin

\begin{tabular}{|c|c|c|c|c|c|c|c|c|c|c|c|c|c|}
\hline \multicolumn{2}{|c|}{ Chlorophyll } & \multicolumn{2}{|c|}{ Carotin } & \multicolumn{2}{|c|}{ Xanthophyll } & \multicolumn{2}{|c|}{$\begin{array}{c}\text { Ethyl chloro- } \\
\text { phyllide }\end{array}$} & \multicolumn{2}{|c|}{ Phytol } & \multicolumn{2}{|c|}{ Pheophytin } & \multicolumn{2}{|c|}{$\begin{array}{c}\text { Copper } \\
\text { pheophytin }\end{array}$} \\
\hline$\lambda$ & $\mathrm{cm}^{-1}$ & $\lambda$ & $\mathrm{cm}^{-1}$ & $\lambda$ & $\mathrm{cm}^{-1}$ & $\lambda$ & $\mathrm{cm}^{-1}$ & $\lambda$ & $\mathrm{cm}^{-1}$ & $\lambda$ & $\mathrm{cm}^{-1}$ & $\lambda$ & $\mathrm{cm}^{-1}$ \\
\hline & & & & & & \multirow{2}{*}{$\begin{array}{r}0.40 \\
.68\end{array}$} & $\begin{array}{l}25,000 \\
14,700\end{array}$ & \multirow{8}{*}{$\begin{array}{l}1.78 \\
2.38 \\
2.96 \\
3.43 \\
4.24 \\
4.91 \\
5.73 \\
5.97\end{array}$} & \multirow{7}{*}{$\begin{array}{l}5,260 \\
4,200 \\
3,380 \\
2,915 \\
2,360 \\
2,035 \\
1,745 \\
1,675\end{array}$} & & & \multirow{5}{*}{$\begin{array}{l}0.98 \\
2.44 \\
4.24\end{array}$} & \multirow{5}{*}{$\begin{array}{l}3,355 \\
2,905 \\
2,360\end{array}$} \\
\hline \multirow{4}{*}{$\begin{array}{l}2.35 \\
2.97 \\
3.43 \\
4.24\end{array}$} & & & & 1.80 & 5,555 & & & & & & & & \\
\hline & 4,255 & & & 2. 35 & 4,255 & & & & & 2.40 & 4,165 & & \\
\hline & 3,365 & 2.92 & 3,425 & 2.95 & 3,390 & 2. 90 & 3,445 & & & 2.98 & 3,355 & & \\
\hline & 2,360 & 4.24 & 2,360 & 4. 24 & 2,360 & & & & & 4.24 & 2,360 & & \\
\hline \multirow{7}{*}{$\begin{array}{l}5.79 \\
5.97 \\
6.20 \\
6.48 \\
6.90 \\
7.30 \\
7.90\end{array}$} & & & & & & \multirow[b]{3}{*}{5.90} & \multirow{3}{*}{1,695} & & & & & & \\
\hline & 1,730 & 5. 79 & 1,730 & & & & & & & 5.80 & 1,725 & 5.75 & 1,740 \\
\hline & $\begin{array}{l}1,675 \\
1,610\end{array}$ & $\begin{array}{l}5.97 \\
6.25\end{array}$ & $\begin{array}{l}1,675 \\
1,600\end{array}$ & $\begin{array}{l}6.01 \\
6.25\end{array}$ & $\begin{array}{l}1,665 \\
1,600\end{array}$ & & & & & \multirow{4}{*}{$\begin{array}{l}6.15 \\
6.48 \\
6.86 \\
7.37\end{array}$} & \multirow{4}{*}{$\begin{array}{l}1,625 \\
1,545 \\
1,460 \\
1,355\end{array}$} & \multirow{6}{*}{$\begin{array}{l}6.15 \\
6.35 \\
6.87 \\
7.32 \\
7.90 \\
8.24 \\
8.60\end{array}$} & \multirow{6}{*}{$\begin{array}{l}1,625 \\
1,575 \\
1,455 \\
1,365 \\
1,265 \\
1,215 \\
1,160\end{array}$} \\
\hline & 1,545 & & & & & \multirow{3}{*}{$\begin{array}{l}6.45 \\
6.90\end{array}$} & \multirow{2}{*}{$\begin{array}{l}1,550 \\
1,450\end{array}$} & & & & & & \\
\hline & 1,450 & 6.90 & 1,450 & 6.89 & 1,450 & & & 6.91 & 1,445 & & & & \\
\hline & $\begin{array}{l}1,370 \\
1,265\end{array}$ & $\begin{array}{l}7.25 \\
8.00\end{array}$ & $\begin{array}{l}1,380 \\
1,250\end{array}$ & $\begin{array}{l}7.30 \\
8.06\end{array}$ & 1,370 & & & 7. 28 & 1,375 & & & & \\
\hline & & & & & & & & 8. 20 & 1,220 & 8. 24 & 1,215 & & \\
\hline 8.60 & 1,160 & 8.70 & 1,150 & 8. 50 & 1,175 & & & 8. 57 & 1,165 & 8. 72 & 1,1 & & \\
\hline 9.58 & 1,045 & & & 9.62 & 1,040 & 9.60 & 1,040 & 9.95 & 1,005 & 9.70 & 1,030 & 9.70 & 1,030 \\
\hline 10.06 & 995 & 10.38 & 965 & 10. 38 & 965 & & & & & 10.23 & 975 & 10.58 & 945 \\
\hline & & 11.25 & 890 & $\begin{array}{l}11.25 \\
11.25\end{array}$ & 890 & & & & & 11. 12 & 900 & & \\
\hline 12.00 & 835 & 12. 10 & 825 & & 835 & 12. 05 & 820 & 12. 23 & 815 & & 820 & 12.04 & 820 \\
\hline 12.60 & 795 & & & 12.83 & 780 & 12.80 & 780 & 12.93 & 775 & & 780 & & 795 \\
\hline 13. 35 & 750 & 13.65 & 730 & & & 13.60 & 735 & 13. 83 & 720 & 13.75 & 725 & 13.70 & 730 \\
\hline
\end{tabular}


It will suffice to call attention to the conspicuous absorption maxima at $3.43 \mu, 4.3 \mu, 6.86 \mu, 7.3 \mu, 9.6 \mu$, and $10.4 \mu$ previously recorded (10) in simpler compounds, particularly chain compounds of $\mathrm{CH}_{2}$ and $\mathrm{CH}_{3}$ groups; also absorption bands at $2.95 \mu, 5.9 \mu$, and $8.6 \mu$, in substances containing COC-, $\mathrm{NH}-$, or $\mathrm{OH}$-bonding. It is impressive to note that both types of absorption bands are present in the herein described compounds which have both types of atomic bonding.

The absorption band at $7.3 \mu$ occurs in common with the band at $6.86 \mu(10)$ and may perhaps be a fundamental as used by Cross and Daniels (12). The recent investigations by Kettering and Sleator (13) of hydrocarbon vapors, to $30 \mu$ in the infrared, show no strong absorption bands beyond about $15 \mu$. From this, it appears highly improbable that the band at $7.3 \mu$ is the result of a combination of fundamentals, one of which is at a wave length longer than $15 \mu$.

\section{BIBLIOGRAPHY}

1. Investigations on Chlorophyll, Methods and Results by R. Willstätter and A. Stoll. Translated by F. M. Schertz and A. R. Merz, 1927.

2. Coblentz and Stair, Phys. Rev. (2), 33, p. 1092, 1929. Preliminary report on carbon tetrachloride, chlorophyll, xanthophyll.

3. Van Gulik, Ann. der Phys., 46, p. 147, 1915.

4. Nichols and Merritt, Phys. Rev., 19, p. 26, 1904. The measurements on chlorophyll in the near infrared were made by Coblentz, using a mirror spectrometer and rock salt prism.

5. Johnson and Spence, Phys. Rev., (2), 5, p. 349, 1915.

6. Mirror spectrometer, B.S.Bull. (S. 204), 10, p. 1, 1913.

7. Iron-clad galvanometers, B.S.Bull. (S 282), 13, p. 423, 1916.

8. Vacuum thermopiles, B.S.Sci. Papers (S 413), 17, p. 187, 1921.

9. Prism material, B.S.Sci. Papers (S 401), 16, p. 701, 1920.

10. Coblentz, Investigation of Infrared Spectra, Publ. No. 35, Carnegie Institution of Washington, 1905. This memoir gives extensive references to, and a discussion of, earlier work (e.g., Julius, Aschkinass, etc.) showing that the absorption spectrum of a compound is not the composite of the absorption spectra of the constituent elements, but is determined by the grouping of the atoms in the molecule.

11. McNicholas, B.S.Jour. Research, 7, p. 171, 1931.

12. Cross and Daniels, Jour. Chemical Physics, 1, p. 48, 1933.

13. Kettering and Sleator, Physics, 4, p. 39, 1933.

14. The increase in wave length of the maximum of selective absorption and of selective reflection in carbonates, nitrates and sulphates, as a function of the atomic weight of the basic element, was first described by Coblentz in the Jahrbuch der Radioaktivität und Elektronik, 4, p. 132, 1907; see also Publications of the Carnegie Institution of Washington, No. 65, and No. 97, 1906 and 1908, respectively.

This phenomenon received favorable comment, at that time, by $\mathrm{E}$. F. Nichols (Washington meeting, Amer. Phys. Soc., April 19, Phys. Rev., (2) 24, p. 522; 1907) who pointed out that he and Prof. H. Rubens had searched for such a shift in the longest residual rays-at $40 \mu$ to $60 \mu$. According to Drude's theory (Ann. der Physik, 14, p. 677; 1904) the maximum absorption of the "ponderable atoms" should occur in the region of $12 \mu$ to $15 \mu$. It is, therefore, of interest to note that Kettering and Sleator (13) find the hydrocarbons relatively transparent and free from bands of selective absorption, for wave lengths longer than $16 \mu$ to $20 \mu$.

Washington, August 7, 1933. 